\title{
Newnham Honored by Turnbull Lectureship
}

Robert Newnham, Alcoa Professor of Solid State Science at The Pennsylvania State University, has been selected as the 1996 recipient of the David Turnbull Lectureship. He was cited for "pioneering the field of ceramic composites for electronic and optical applications, and in recognition of a distinguished career of guiding students, lecturing, and writing." The David Turnbull Lectureship recognizes the career of a scientist who has made outstanding contributions to understanding materials phenomena and properties through research, writing, and lecturing, as exemplified by David Turnbull.

Widely known as a gifted scientist and teacher in the materials community, Newnham developed the concept and nomenclature for electrically active ceramic composites. He was responsible for not only the theory behind these composites, but also for their translation into "smart" materials and devices (a term he coined).

Composite materials have found a number of structural applications, but their use in electronics is surprisingly widespread but unrecognized. Newnham has developed a number of concepts to apply composite materials to electronics-sum and product properties (which involve a property from multiple constituents or combining different properties of multiple phases), connectivity patterns (which determine field and force concentration), the importance of periodicity and scale in resonant structures, the symmetry of composite materials and its influence on physical properties, polychromatic percolation and coupled conduction paths in composites, varistor action and other interfacial effects, coupled phase-transformation phenomena in composites, and the important role that porosity and inner surface area play in many composite sensors.

Based on the newly discovered "repla-

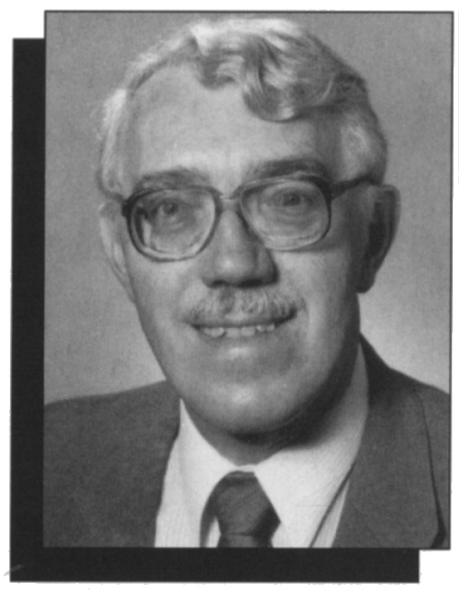

mine form" process for making what he would later designate as 3-3 composites, Newnham (and colleague L.E. Cross) designed the first composite of lead zirconate titanate (PZT, the well-known transducer material $\left.\mathrm{Pb}\left(\mathrm{Ar}_{1-x} \mathrm{Ti}_{x}\right) \mathrm{O}\right)$ and polymer that increased the figure of merit of electromechanical transducers by a factor of $10^{3}$. In the replamine process, a natural structure is copied in other materials by a "lostwax" technique similar to that used by sculptors. Based on his thorough understanding of the interaction of a tailored composite microstructure with the electromagnetic spectrum, he went on to design dozens of composites for specific applications. He recently applied the same principles to smart systems by designing unique sensor and actuator combinations specific to the task.

Newnham is known as an innovator, including complex composite sensors based on the biomimetic principles learned from the bat's ear, and fish bladders used for emitting grunts. He has incorporated several materials into real devices, with many of them entering real- world products. As an academician, he is unusual in moving along the continuum of pure theory to material to device to commercialization.

As a lecturer, Newnham is known around the world for exceptional clarity and organization, and as a graduate student advisor, his students has captured 23 of the annual Xerox awards (eight jointly supervised) given annually at Penn State for the best thesis in materials in any department on campus.

Robert Newnham received a BS degree in mathematics from Hartwick College in 1950; an MS degree in physics from Colorado State University in 1952; and two PhD degrees, one in physics from The Pennsylvania State University (1956), and a second in crystallography from Cambridge University (1960). He was a research fellow at Cavendish Laboratory, Cambridge, from 1956 to 1958 , when he joined the Massachusetts Institute of Technology (MIT). After eight years at MIT, he then joined the faculty at Penn State, where he is now Associate Director and Alcoa Professor of Solid State Science, Intercollege Materials Research Laboratory and Department of Materials Science and Engineering.

Newnham has published more than 400 research papers, written four books and 14 book chapters or review articles, served in an editorial capacity on eight journals, guest edited the April 1993 issue of MRS Bulletin, and received more than 30 honors. He is a fellow of the Mineralogical Society of America and the American Ceramic Society, and a member of the National Academy of Engineering.

Newnham will deliver the Turnbull Lecture, "Molecular Mechanisms in Smart Materials," on Monday, December 2 at 10 a.m. in session Y1.5, Commonwealth Room, Sheraton Boston Hotel.

\section{GRADUATE STUDENT AWARDS}

The Materials Research Society announces the availability of several awards for graduate students conducting research on a topic to be addressed in the symposia planned for the 1997 Spring Meeting. Each award will consist of a cash grant of $\$ 250$, a plaque which will be presented at the Plenary Session during the meeting, and a waiver of the meeting registration fee.

\section{Deadline for completed application is December 27, 1996.}

Obtain application information from John B. Ballance, Executive Director, Materials Research Society, 9800 McKnight Road, Pittsburgh, PA 15237-6006, USA; 412-367-3003; fax 412-367-4373, or e-mail info@mrs.org. 